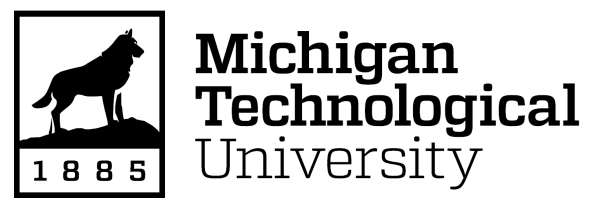

Michigan Technological University Digital Commons @ Michigan Tech

6-18-2013

\title{
Shape-induced gravitational sorting of Saharan dust during transatlantic voyage: Evidence from CALIOP lidar depolarization measurements
}

Weidong Yang

Universities Space Research Association

Alexander Marshak

NASA Goddard Space Flight Center

Alexander Kostinski

Michigan Technological University

Tamás Várnai

University of Maryland - Baltimore County

Follow this and additional works at: https://digitalcommons.mtu.edu/physics-fp

Part of the Physics Commons

\section{Recommended Citation}

Yang, W., Marshak, A., Kostinski, A., \& Várnai, T. (2013). Shape-induced gravitational sorting of Saharan dust during transatlantic voyage: Evidence from CALIOP lidar depolarization measurements. Geophysical Research Letters, 40(12), 3281-3286. http://dx.doi.org/10.1002/grl.50603

Retrieved from: https://digitalcommons.mtu.edu/physics-fp/184

Follow this and additional works at: https://digitalcommons.mtu.edu/physics-fp

Part of the Physics Commons 


\title{
Shape-induced gravitational sorting of Saharan dust during transatlantic voyage: Evidence from CALIOP lidar depolarization measurements
}

\author{
Weidong Yang, ${ }^{1,2}$ Alexander Marshak, ${ }^{2}$ Alexander B. Kostinski, ${ }^{3}$ and Tamás Várnai ${ }^{2,4}$ \\ Received 22 March 2013; revised 21 May 2013; accepted 28 May 2013; published 18 June 2013.
}

[1] Motivated by the physical picture of shape-dependent air resistance and, consequently, shape-induced differential sedimentation of dust particles, we searched for and found evidence of dust particle asphericity affecting the evolution and distribution of dust-scattered light depolarization ratio $(\delta)$. Specifically, we examined a large data set of Cloud-Aerosol Lidar with Orthogonal Polarization (CALIOP) observations of Saharan dust from June to August 2007. Observing along a typical transatlantic dust track, we find that (1) median $\delta$ is uniformly distributed between 2 and $5 \mathrm{~km}$ altitudes as the elevated dust leaves the west coast of Africa, thereby indicating uniformly random mixing of particle shapes with height; (2) vertical homogeneity of median $\delta$ breaks down during the westward transport: between 2 and $5 \mathrm{~km} \delta$ increases with altitude and this increase becomes more pronounced with westward progress; (3) $\delta$ tends to increase at higher altitude $(>4 \mathrm{~km})$ and decrease at lower altitude $(<4 \mathrm{~km})$ during the westward transport. All these features are captured qualitatively by a minimal model (two shapes only), suggesting that shape-induced differential settling and consequent sorting indeed contribute significantly to the observed temporal evolution and vertical stratification of dust properties. By implicating particle shape as a likely cause of gravitational sorting, these results will affect the estimates of radiative transfer through Saharan dust layers. Citation: Yang, W., A. Marshak, A. B. Kostinski, and T. Várnai (2013), Shape-induced gravitational sorting of Saharan dust during transatlantic voyage: Evidence from CALIOP lidar depolarization measurements, Geophys. Res. Lett., 40, 3281-3286, doi:10.1002/grl.50603.

\section{Introduction}

[2] Accurate estimation of net radiative influence of dust is difficult because of the complex temporal and spatial variations in dust properties. Dust optical properties vary with the chemical composition [e.g., Sokolik and Toon, 1999; Petzold et al., 2009] and size of particles, and can change as dust interacts with other substances in the air

\footnotetext{
${ }^{1}$ Goddard Earth Sciences Technology and Research, Universities Space Research Association, Columbia, Maryland, USA.

${ }^{2}$ NASA Goddard Space Flight Center, Greenbelt, Maryland, USA

${ }^{3}$ Department of Physics, Michigan Technological University, Houghton Michigan, USA.

${ }^{4}$ Joint Center for Earth System Technology, University of Maryland at Baltimore County, Baltimore, Maryland, USA.

Corresponding author: W. Yang, Goddard Earth Sciences Technology and Research, Universities Space Research Association, Columbia, MD 21044, USA. (Weidong.Yang@nasa.gov)

(C2013. American Geophysical Union. All Rights Reserved. 0094-8276/13/10.1002/grl.50603
}

[e.g., Levin et al., 1996; Trochkine et al., 2003]. In addition, the scattering and absorbing properties of dust are also affected by particle shape [Kalashnikova and Sokolik, 2002; Dubovik et al., 2006; Nousiainen, 2009]. For example, the asphericity of particles can enhance forward scattering and reduce back scattering and can make single scattering albedo and extinction coefficient different from their spherical counterparts. Hence, particle asphericity needs to be considered in dust radiative forcing calculations. To that end, we recall that particle shape affects air resistance (drag) as well and can, therefore, influence the vertical distribution of dust properties during transatlantic transport. Hence, the radiative and fluid-mechanical aspects of dust transport can be linked via particle shape and we now proceed to employ this link.

[3] Because of higher drag, at a given volume and mass, aspherical particles fall more slowly and hence stay aloft longer than their spherical counterparts. Note that this is particularly pronounced for lower Reynolds numbers (laminar regime). Theoretical calculations show that the fall speed can be significantly affected when the aspect ratio (ratio of major axis to the minor axis of an ellipsoid) exceeds 1.5. For example, an aspect ratio change from 1 to 5 reduces fall speeds by about $30 \%$ and $50 \%$ for particles smaller than $1.0 \mu \mathrm{m}$ and within the $10-20 \mu \mathrm{m}$ range, respectively [e.g., Cheng et al., 1988; Ginoux, 2003]. Therefore, one would expect populations of irregular particles and spherical particles of the same mass and density to gradually separate, and dust layers to stratify, with the eventual preponderance of the most aspherical particles at the top as illustrated schematically in Figure 1. Our observations suggest that such processes may actually occur under ambient conditions.

\section{Methodology and Data}

[4] Here we exploit the fact that the depolarization of lidar backscatter signal (echo) is determined primarily by particle shape [e.g., Ansmann, 2003]. The depolarization ratio is defined as the ratio of an echo's cross-polarized and copolarized components. CALIOP (Cloud-Aerosol Lidar with Orthogonal Polarization) provides two types of depolarization ratio: volume depolarization ratio and particulate depolarization ratio. Since the particulate depolarization ratio is free of contributions from molecular scattering and attenuation, whereas the volume depolarization ratio is influenced by both, the particulate depolarization ratio is more suitable for describing the properties of dust itself. Therefore, depolarization ratio henceforth refers to "particulate depolarization ratio", denoted as $\delta$. This ratio is zero for spherical particles but not for aspherical ones. 


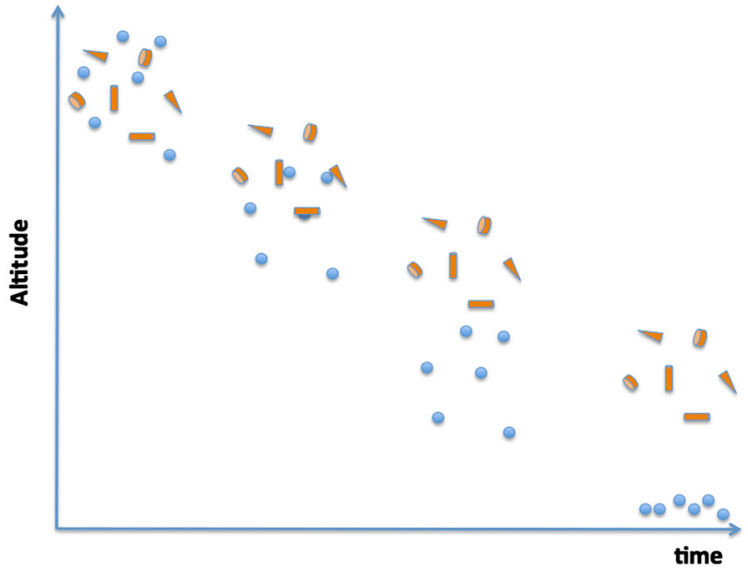

Figure 1. Schematic illustration of shape-induced differential sedimentation: because of the higher settling speed of spherical particles, the initially mixed groups of spherical (blue) and aspherical (orange) particles (all at the same mass and volume), gradually separate, creating a stratified structure with the preponderance of aspherical particles at the top.

[5] In this study, we use $\delta$ observations for Saharan dust to infer the effects of shape on dust settling and on the resulting vertical structures. Specifically, we use dust data provided by the CALIOP lidar onboard the Cloud Aerosol-Lidar and Infrared Pathfinder Satellite Observations (CALIPSO) satellite [e.g., Winker et al., 2003; Vaughan et al., 2004]. CALIPSO was launched in 2006 and provides rangeresolved cloud and aerosol data along its track, including total lidar backscatter at $532 \mathrm{~nm}$ and $1064 \mathrm{~nm}$, and perpendicularly polarized lidar backscatter at $532 \mathrm{~nm}$. CALIPSO operational algorithms (currently in Version 3) use this data along with altitude and latitude information for feature identification and classification, [e.g., Liu et al., 2009; Omar et al., 2009].

[6] This study is based on nighttime data from the three summer months in 2007 over the North Atlantic region $\left(0^{\circ} \mathrm{N}-30^{\circ} \mathrm{N}, 0^{\circ} \mathrm{W}-90^{\circ} \mathrm{W}\right)$ shown in Figure $2 \mathrm{a}$. This time period and region were selected in order to include the typical transport path of African desert dust outbreaks. The main advantage of nighttime data is a much higher signal-to-noise ratio. The study includes about 300 satellite tracks and more than $10^{6}$ laser shots within the selected North Atlantic region. To detect longitudinal variations in the vertical distribution of dust depolarization ratio, we subdivide the North Atlantic into nine consecutive strips, labeled sequentially with increasing distance from the west coast of Africa (Figure 2a). Note that the nine regions are sufficiently large to yield adequate statistics with low noise levels, yet sufficiently small to constrain regional variability.

[7] Let us now examine the vertical distribution of $\delta$ (dust particulate depolarization ratio) using CALIOP dust data provided at $5 \mathrm{~km}$ horizontal resolution. The CALIOP aerosol layer product delivers vertically averaged particulate depolarization ratio for each aerosol layer by removing the contributions from molecular Rayleigh scattering and attenuation. Our analysis keeps the noise level low by aggregating statistics over each of the nine $10^{\circ}$ by $30^{\circ}$ regions at 270 or $540 \mathrm{~m}$ vertical resolution. A dust sample is counted in an altitude bin if the dust layer top and base altitudes in the CALIOP aerosol layer product indicate that the altitude bin contains dust within a $5 \mathrm{~km}$-resolution segment. The depolarization ratio of the dust layer is then included into the statistics of this altitude bin. In order to reduce interference from clouds, only dust layers in fully cloud-free columns are used (with no clouds identified by either the $0.333 \mathrm{~km}, 1 \mathrm{~km}$, or $5 \mathrm{~km}$ resolution CALIOP cloud
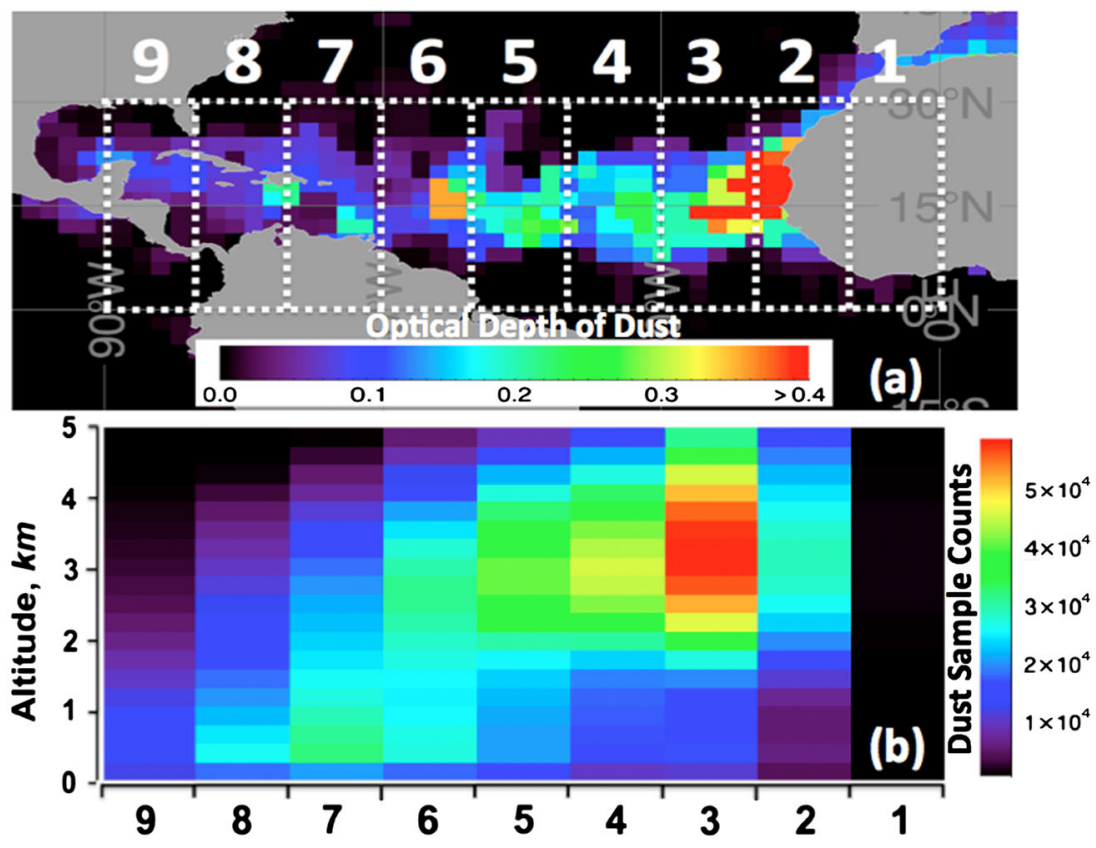

Figure 2. (a) Positioning of the nine consecutive regions studied along the typical summertime track of Saharan dust. Colors encode values of the median optical depth of dust layers at $2^{\circ}$ by $2^{\circ}$ horizontal resolution. (b) Vertical distribution of the number of $5 \mathrm{~km}$-resolution dust samples in the nine regions. Each bin has a height of $270 \mathrm{~m}$. 


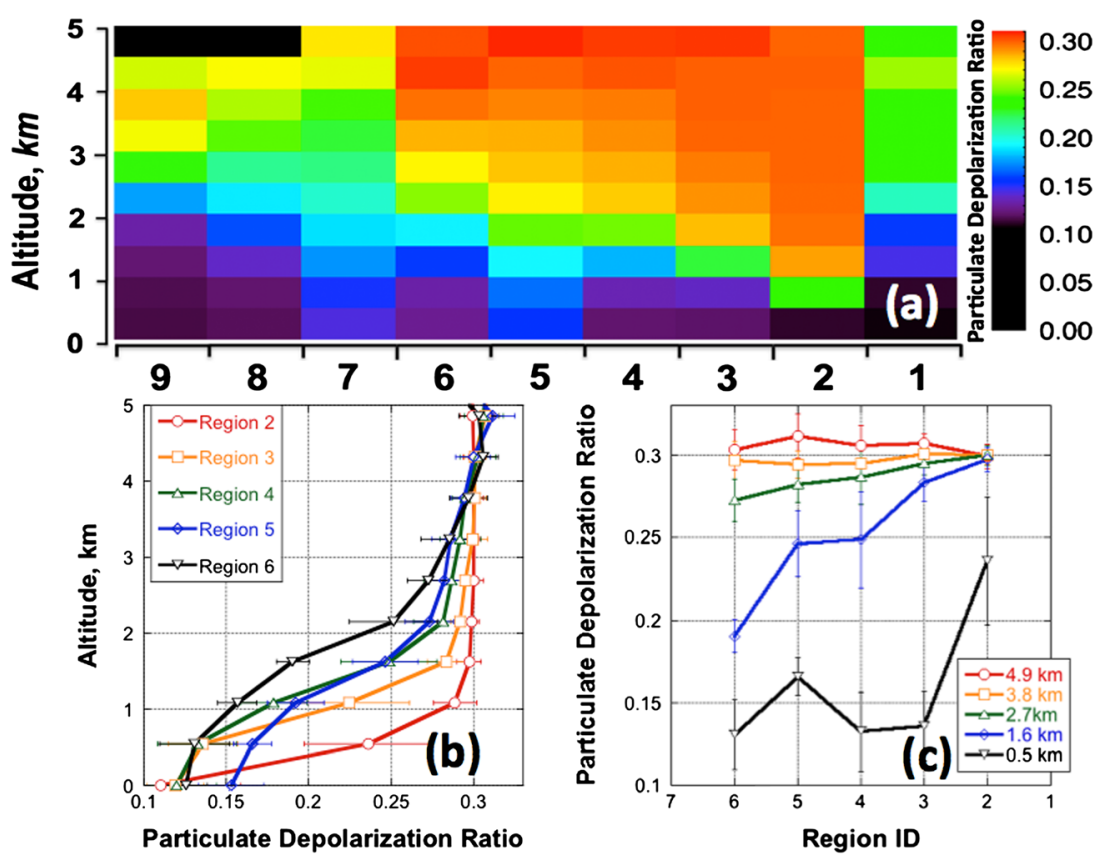

Figure 3. Median of dust particulate depolarization ratio $\delta$ : (a) as a function of altitude in the nine regions; (b) as a function of altitude in Regions 2 to 6; (c) as a function of longitude-regions. The vertical resolution is $540 \mathrm{~m}$. Uncertainties in median estimates are calculated by the bootstrapping algorithm [Efron and Gong, 1983]. As the dust leaves the west coast of Africa (Region 2), the $\delta$ values at all altitudes above $\sim 2 \mathrm{~km}$ are about the same but in the course of westward transport, the depolarization spreads out with higher ratios at higher altitudes. Furthermore, the depolarization ratio lapse rate increases westward. The altitude-independent $\delta$ in Region 2 indicates that particles of various shapes are randomly mixed throughout the atmospheric column. The progressive westward dispersion of $\delta$ suggests a separation of dust by shape-induced differential settling. The longer time causes wider vertical separation, and consequently, a higher lapse rate of the vertically increasing $\delta$ is observed with westward transport. See text for more details.

products within the entire $5 \mathrm{~km}$ segment). Finally, we constrain misclassification between ice clouds and dust by considering only data below $5 \mathrm{~km}$, as ice clouds during summer in the examined region seldom occur below this altitude.

\section{Results and Discussion}

[8] The vertical structure of the number of dust samples and of the median particulate depolarization ratio in our CALIOP dust data set is shown in Figures $2 \mathrm{~b}$ and 3 . Figure $2 \mathrm{~b}$ indicates that most dust samples are between $1.5 \mathrm{~km}$ and $5 \mathrm{~km}$ with a median altitude around $3.0-3.5 \mathrm{~km}$ while dust traverses Regions 2 through 5. The dust sample vertical distribution changes in Region 6 and most of the dust samples are well below $3 \mathrm{~km}$ in Regions 7 to 9. In addition, more dust samples are found in regions closer to the west coast of Africa, except for Region 2 that has a smaller number of samples because only half of this region is covered by ocean. Because Region 1 is mostly covered by land and the number of its dust samples over ocean is very small, this region will be excluded from further consideration. It is noted that as dust outbreaks occur frequently in summers [Huang et al., 2010], the chosen data set contains many outbreaks without having to combine data from different seasons.

[9] Figure 3a depicts the vertical profiles of particulate depolarization ratio for the dust samples shown in Figure $2 \mathrm{~b}$. In order to highlight the most important features, Figures $3 b$ and $3 c$ present crosssections of the results from Figure $3 \mathrm{a}$ for Regions 2-6. The main features can be summarized as follows. (1) While the number of dust samples peaks around $3-3.5 \mathrm{~km}$ altitude in Regions $2-6$ and below $1.5 \mathrm{~km}$ in Regions 7-9, the dust depolarization ratios in all regions increase with altitude; (2) In Region 2, closest to west coast of Africa, the median depolarization ratio is around $\sim 0.3$ and is fairly constant between $1.5 \mathrm{~km}$ and $5 \mathrm{~km}$ altitudes. This indicates that near the source all shapes are mixed throughout the column; (3) In Figures 3b-3c, the dust depolarization ratios in each of Regions 2-5 are larger than in their eastern neighbors at altitudes above $4 \mathrm{~km}$, but smaller at $1.5-4 \mathrm{~km}$. This implies a clear increase in the lapse rate of $\delta$ during westward transport.

[10] The basic features described above are consistent with the shape-induced differential settling of dust particles. To illustrate this process, let us consider a minimal model: settling of only two spheroid particle shapes, with aspect ratios $\lambda_{1}$ and $\lambda_{2}$. The initial vertical distribution of total samples at $t=0$ time is then $f^{o}(h)=f^{o}{ }_{1}(h)+f^{o}{ }_{2}(h)$ where $f^{o}{ }_{1}(h)$ and $f^{o}{ }_{2}(h)$ are the initial vertical distributions of samples for the two particle shapes. We further assume that all particles have the same density and mass, and hence mass-equivalent size. This two-shape, one-size assumption is plausible because measurements do not show significant dependence of aspect ratio on particle size [e.g., Reid et al., 2003], allowing us to disentangle shape and size effects. Because higher aspect ratio corresponds to lower settling speed $(v)$ and higher depolarization ratio $(\delta)$, a relationship $\lambda_{1}>\lambda_{2}$ in our simple dust layer implies $v_{1}<v_{2}$, and $\delta_{1}>\delta_{2}$.

[11] Due to shape-induced differential settling, the two kinds of particles, at first evenly mixed throughout atmospheric columns, will gradually separate during westward 

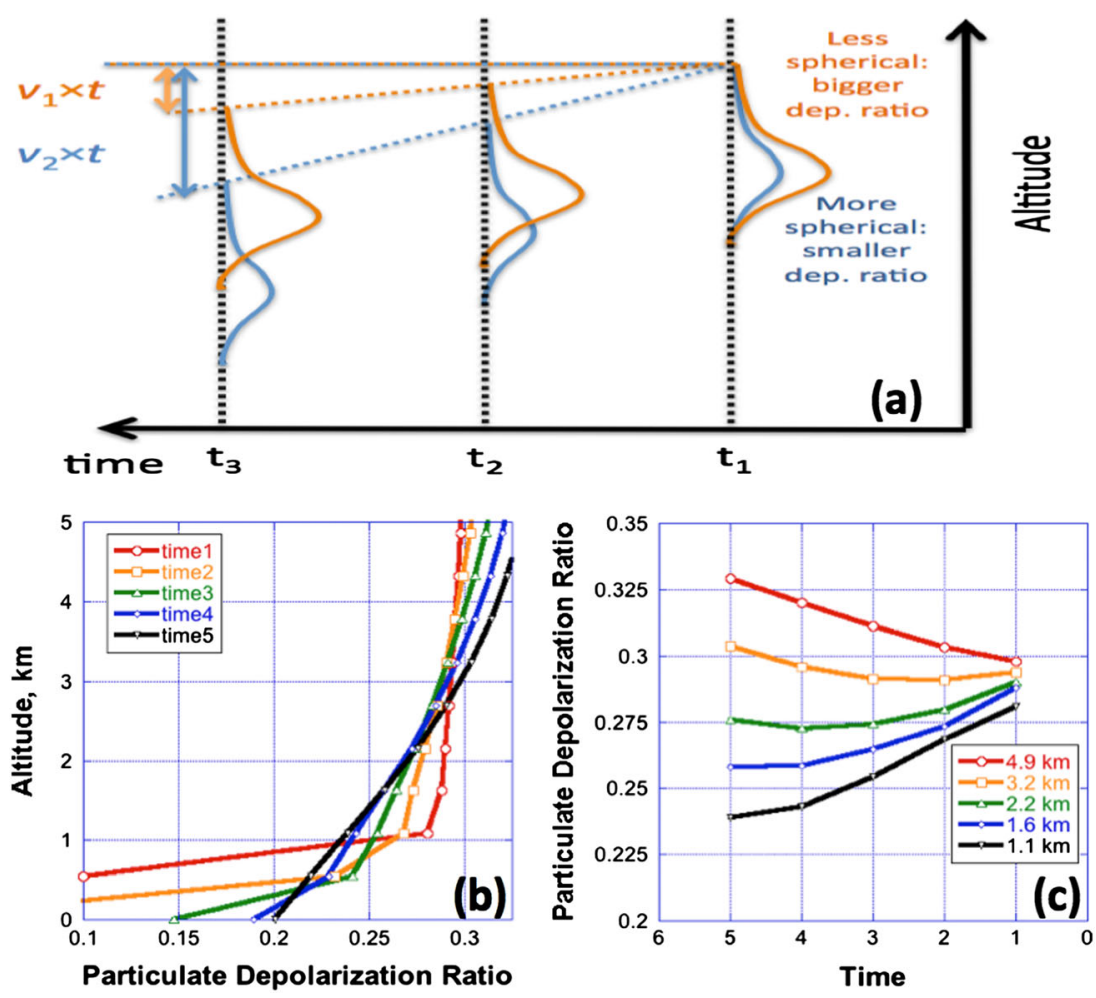

Figure 4. Illustration of shape-dependent settling in a minimal two-shape one-size model of differential dust settling. (a) Schematic illustration of a shape-induced vertical separation of dust populations. (b) Simulated temporal evolution of depolarization ratio $\delta$ vertical distribution when the two groups of dust particles are well mixed initially, and have Gaussian vertical distributions. (c) The temporal evolution of the depolarization ratio at different altitudes. Figures $4 \mathrm{~b}$ and $4 \mathrm{c}$ display features that are similar to those of the CALIOP observations in Figures $3 \mathrm{~b}$ and $3 \mathrm{c}$. See text for details. Note that this model does not include contributions from possible retrieval errors due to instrument/algorithm uncertainties or to mixing or interactions with other components in the atmosphere.

transport, resulting in particle populations with larger aspect and depolarization ratios at higher altitudes, as shown in Figure 4a. This behavior agrees well with the observations, which show larger $\delta$ values at higher altitudes after dust leaves the west coast of Africa (Figure 3). The separation of the two groups of particles increases with time, and eventually particles of $\lambda_{1}$ dominate and a maximum $\delta_{1}$ is reached at high altitudes, while particles of $\lambda_{2}$ dominate and a minimum $\delta_{2}$ is reached at low altitudes. Overall, with westward progress, $\delta$ increases (decreases) monotonically at high (low) altitudes and the lapse rate of $\delta$ also increases as seen in Figure 3.

[12] The above scenario of two-shape one-size dust layers can be formalized as follows: if the shapes of function $f^{o}{ }_{1}(h)$ and $f_{2}^{o}(h)$ do not change significantly during the settling process, the vertical distribution of dust samples becomes $f(h, t)=f_{1}(h, t)+f_{2}(h, t)$ where $f_{1}(h, t)=f^{o}{ }_{1}(h+v \bullet t)$ and $f_{2}$ $(h, t)=f_{2}^{o}\left(h+v_{2} \bullet t\right)$ are the two dust sample vertical distributions at time $t$, correspondingly. Additionally, the average $\delta$ can be estimated using $\delta(h, t)=\left[\delta_{1} \bullet(1-\alpha)+\delta_{2} \bullet \alpha\right]$ where $\alpha=f_{2}(h, t) /\left[f_{1}(h, t)+f_{2}(h, t)\right]$ is the relative weight of dust particles with $\lambda_{2}$ and ranges from 0 to 1 .

[13] Figures $4 b$ and $4 c$ depict the evolution of depolarization ratios arising from the shape-dependent settling mechanism of the minimal model illustrated in Figure $4 \mathrm{a}$. The results are qualitatively consistent with those in Figure 3, suggesting that the basic features of CALIOP observations come from shape-dependent sedimentation. In this numerical illustration, we selected parameters based on the following: (1) because $\lambda$ most frequently occurs around 1.5 and ranges from 1 to 5 [e.g., Ginoux, 2003] and because $\delta$ has relatively distinguishable values around $\lambda \sim 1.2$ [Mishchenko and Hovenier, 1995], we choose $\lambda_{1}=2.7$ (at the larger end of recent measurements by Kandler et al. [2009] but below the average $\lambda$ of 1.2 and 5) and $\delta_{1}=0.4$ [Sakai et al., 2010] for the first group of particles, and $\lambda_{2}=1.1$ (the average $\lambda$ of 1 and 1.2) and $\delta_{2}=0.1$ for the second group; (2) additionally, since the typical size is $\sim 7 \mu \mathrm{m}$ in diameter for transatlantic dust [Ginoux, 2003], we choose $v_{2} \sim 1600 \mathrm{~cm} / \mathrm{hr}$ (nearly spherical particle because of $\left.\lambda_{2} \sim 1.1\right)$ and $v_{1}=v_{2}(1-0.2)$ where 0.2 is the fall speed reduction rate for $\lambda_{1}$ and is estimated from the theoretical reductions in fall speed for $\lambda=1$ and $\lambda=5$ for $7 \mu \mathrm{m}$ size [e.g., Ginoux, 2003]; and (3) finally, the initial distribution functions of $f^{o}{ }_{1}(h)$ and $f^{o}{ }_{2}(h)$ are set to be Gaussian functions with a mean altitude of $4.5 \mathrm{~km}$ and standard deviation of $3 \mathrm{~km}$. The illustrated $\delta$ vertical distributions are the averages over $24 \mathrm{~h}$-long time spans. While a skeptical reader might object that these values chosen for the model parameters are somewhat arbitrary, it should be noted that the key features of the results hold for a wide range of values used in our simulations. The differences between the model and CALIOP observations are mostly in the specific values such as the altitude of depolarization ratio at which $\delta$ in a certain region surpasses $\delta$ in the preceding region. Generalizing to several aspect ratios and size distributions readily reduces these differences. Note that 
although altitudes below $2 \mathrm{~km}$ are displayed in our figures, one should not compare observations and simulations below $2 \mathrm{~km}$, because CALIOP observations are affected by nearly spherical marine aerosols at these altitudes.

[14] While shape-dependent sedimentation has been examined in theoretical studies [e.g., Ginoux, 2003], to our knowledge, no link of this process to observations has ever been attempted. This may be due to limitations in the available observations, such as the large noise in measurements of $\delta$ or insufficient spatial coverage and duration of observations. Our CALIOP data set of transatlantic dust over a summer season reveals that the shape-dependent settling and the resulting shape-dependent layer structure are significant at oceanic and seasonal scales. This is consistent with the earlier studies that characterized African dust during the Puerto Rico Dust Experiment and found dust to have a significantly higher aspect ratio near 1.9 after long-range transport [Reid et al., 2003, p. 7-9].

[15] Are there alternative explanations? Consider, for example, the formation of loose aggregates that can lead to the higher aspect ratios and trigger shape-dependent settling. While aggregation could explain the westward increase in $\delta$ (and may contribute to it), it does not readily explain the increase of $\delta$ with altitude. We considered several other plausible explanations such as shape softening via humidification, etc. but to no avail. For example, in humidification, it seems unlikely that circumstances would conspire to supply just the right evolving humidity profiles, with westward increase in humidity at higher (but not lower) altitudes. Finally, mixing spherical marine aerosols into the Saharan Air Layer (SAL) from below is unlikely to cause the $\delta$-drop at altitudes between 2 and $4 \mathrm{~km}$ in westward Regions 2-5 (in Figure 3c), because this mixing at such altitudes and regions is rare due to the confinement of marine boundary layer by the SAL.

[16] Could these CALIPSO observations be spurious, i.e., attributed to algorithmic artifacts? Indeed, CALIPSO dust $\delta$ values are retrieved quantities that mostly rely on a predefined lidar ratio. Because this predefined lidar-ratio is a constant, it cannot follow the fluctuations of dust size and density that play a role in multiple scattering and thus, in the ideal lidar-ratio values [Wandinger et al., 2010]. As such, a constant lidar-ratio could conceivably lead to a westward and upward increasing bias of $\delta$ s as large particles settle out gradually during transport multiple scattering is reduced. Then, a higher lidar-ratio is required to compensate for loosing large particles. However, this mechanism does not lead to the westward decreasing trend of depolarization ratio at 2 $4 \mathrm{~km}$ in Regions 2-5 observed by CALIPSO (Figure 3c). Moreover, the CALIPSO $\delta$ retrieval is not sensitive to the lidar ratio [Liu et al., 2013], and the backscatter coefficient retrievals compare well with the ground measurements [Wandinger et al., 2010]. Therefore, the observed trend in particulate depolarization ratio is more likely ascribed to shape-induced sedimentation.

\section{Concluding Remarks}

[17] In this study we asked: Does the effect of particle shape on differential sedimentation cause an evolving vertical stratification as dust plumes are transported westward across the Atlantic? If so, such stratification should be discernible from CALIOP data on $\delta$. We then searched for and discovered evidences of dust particle asphericity affecting the evolution and patterns of scattered light depolarization ratio $(\delta)$.

[18] Specifically, shape-induced gravitational sorting is evidenced by the summertime observations of evolving patterns in lidar signal depolarization measurements from the CALIPSO satellite. Here we demonstrate that even a minimal two-shape one-size model of dust particle settling captures qualitatively the basic features of observations. The results show a clearly increasing stratification in $\delta$ as dust moves. Finally, we note that knowledge of dust vertical distributions can improve the accuracy of aerosol optical depth and particle size retrievals. For example, in optically thick dust layers, particle properties near the top can affect satellite observations more than those at lower altitudes, thus the assumption of vertical homogeneity in dust property retrievals can lead to biased results when the vertical distribution of particle shape is inhomogeneous. Therefore, our results imply that particle shape-dependent settling (hence the induced vertical distribution of $\delta$ ) is important not only in studies of dust transport and sedimentation but also in estimating dust optical properties, radiative forcing, and dust loading.

[19] Acknowledgments. We gratefully acknowledge support for this research by the NASA Radiation Sciences Program managed by Hal Maring, by the NASA CALIPSO project supervised by Charles Trepte as the technical officer, and by NSF through grant AGS-1119164. We also thank Peter Colarco, Ralph Kahn, Robert Levy, Zhaoyan Liu, Yuekui Yang, Hongbin Yu, and Tianle Yuan for their helpful suggestions. We are also grateful for the insightful comments by the anonymous referees.

[20] The Editor thanks two anonymous reviewers for their assistance in evaluating this paper.

\section{References}

Ansmann, A., et al. (2003), Long-range transport of Saharan dust to northern Europe: The 11 - 16 October 2001 outbreak observed with EARLINET, J. Geophys. Res., 108(D24), 4783, doi:10.1029/2003JD003757.

Cheng, Y.-S., H.-C. Yeh, and M. D. Allen (1988), Dynamic shape factor of a plate-like particle, Aerosol Sci. Technol., 8, 109-123.

Dubovik, O., et al. (2006), Application of spheroid models to account for aerosol particle nonsphericity in remote sensing of desert dust, J. Geophys. Res., 111, D11208, doi:10.1029/2005JD006619.

Efron, B., and G. Gong (1983), A leisurely look at the bootstrap, the jackknife, and cross-validation, Am. Stat., 37, 36-48.

Ginoux, P. (2003), Effects of nonsphericity on mineral dust modeling, J. Geophys. Res., 108(D2), 4052, doi:10.1029/2002JD002516.

Huang, J., C. Zhang, and J. M. Prospero (2010), African dust outbreaks: A satellite perspective of temporal and spatial variability over the tropical Atlantic Ocean, J. Geophys. Res., 115, D05202, doi:10.1029/2009JD012516.

Kalashnikova, O. V., and I. N. Sokolik (2002), Importance of shapes and compositions of wind-blown dust particles for remote sensing at solar wavelengths, Geophys. Res. Lett., 29(10), 1398, doi:10.1029/2002GL014947.

Kandler, K., et al. (2009), Size distribution, mass concentration, chemical and mineralogical composition and derived optical parameters of the boundary layer aerosol at Tinfou, Morocco, during SAMUM 2006, Tellus, Ser., B, 61, 32-50, doi:10.1111/j.1600-0889.2008.00385.x.

Levin, Z., E. Ganor, and V. Gladstein (1996), The effects of desert particles coated with sulfate on rain formation in the eastern Mediterranean, J. Appl. Meteorol., 35, 1511-1523.

Liu, Z., M. Vaughan, D. Winker, C. Kittaka, B. Getzewich, R. Kuehn, A. Omar, K. Powell, C. Trepte, and C. Hostetler (2009), The CALIPSO lidar cloud and aerosol discrimination: Version 2 algorithm and initial assessment of performance, J. Atmos. Oceanic Technol., 26, 1198-1213, doi:10.1175/2009JTECHA1229.1.

Liu, Z., et al. (2013), Transpacific transport and evolution of the optical properties of Asian dust, J. Quant. Spectrosc. Radiat. Transfer, 116, 24-33, doi:10.1016/j.jqsrt.2012.11.011.

Mishchenko, M. I., and J. W. Hovenier (1995), Depolarization of light backscattered by randomly oriented nonspherical particles, Opt. Lett., 20, 1356-1358

Nousiainen, T. (2009), Optical modeling of mineral dust particles: A review, J. Quant. Spectrosc. Radiat. Transfer, 110, 1261-1279. 


\section{YANG ET AL.: SHAPE-INDUCED SORTING OF SAHARAN DUST}

Omar, A. H., et al. (2009), The CALIPSO automated aerosol classification and lidar ratio selection algorithm, J. Atmos. Oceanic Technol., 26, 1994-2014, doi:10.1175/2009JTECHA1231.1.

Petzold, A., et al. (2009), Saharan dust absorption and refractive index from aircraft-based observations during SAMUM 2006, Tellus, Ser. B, 61, 118-130, doi:10.1111/j.1600-0889.2008.00383.x.

Reid, E. A., J. S. Reid, M. M. Meier, M. R. Dunlap, S. S. Cliff, A. Broumas, K. Perry, and H. Maring (2003), Characterization of African dust transported to Puerto Rico by individual particle and size segregated bulk analysis, J. Geophys. Res., 108(D19), 8591, doi:10.1029/2002JD002935.

Sakai, T., T. Nagai, Y. Zaizen, and Y. Mano (2010), Backscattering linear depolarization ratio measurements of mineral, sea-salt, and ammonium sulfate particles simulated in a laboratory chamber, Appl. Opt., 49(23), 4445.

Sokolik, I., and O. Toon (1999), Incorporation of mineralogical composition into models of the radiative properties of mineral aerosol from UV to IR wavelengths, J. Geophys. Res., 104, 9423-9444.
Trochkine, D., Y. Iwasaka, A. Matsuki, M. Yamada, Y.-S. Kim, T. Nagatani, D. Zhang, G.-Y. Shi, and Z. Shen (2003), Mineral aerosol particles collected in Dunhuang, China, and their comparison with chemically modified particles collected over Japan, J. Geophys. Res., 108(D23), 8642, doi:10.1029/2002jd003268

Vaughan, M. A., S. Young, D. Winker, K. Powell, A. Omar, Z. Liu, Y. Hu, and C. Hostetler (2004), An overview of the CALIPSO retrieval algorithms and data products, in Laser Radar Techniques for Atmospheric Sensing, edited by U. N. Singh, Proceedings of SPIE Vol. 5575.

Wandinger, U., M. Tesche, P. Seifert, A. Ansmann, D. Müller, and D. Althausen (2010), Size matters: Influence of multiple scattering on CALIPSO light-extinction profiling in desert dust, Geophys. Res. Lett., 37, L10801, doi:10.1029/2010GL042815.

Winker, D. M., J. Pelon, and M. P. McCormick (2003), The CALIPSO mission: Spaceborne lidar for observation of aerosols and clouds, Proc. SPIE 4893, 1 doi:10.1117/12.466539. 